\title{
Bone Mineral Density in Patients with Newly Diagnosed Inflammatory Bowel Disease: Frequency and Risk Factors in Tunisian Population. Results of a Prospective Study
}

\author{
Myriam Cheikh1,2*, Taieb Jomni'2,3, Wassila Bougassas ${ }^{1,2}$, Lamia Ben Yaghlène ${ }^{2,3}$, \\ Mohamed Hedi Douggui 2,3 \\ ${ }^{1}$ Department of Hepato-Gastro-Enterology, Mongi Slim Hospital, Tunis, Tunisia \\ ${ }^{2}$ Faculty of Medicine, University of Tunis El Manar, Tunis, Tunisia \\ ${ }^{3}$ Department of Gastroenterology of the Internal Security Forces Hospital, Tunis, Tunisia \\ Email: "cheikh.myriam@gmail.com
}

Received 22 September 2015; accepted 2 November 2015; published 5 November 2015

Copyright @ 2015 by authors and Scientific Research Publishing Inc.

This work is licensed under the Creative Commons Attribution International License (CC BY). http://creativecommons.org/licenses/by/4.0/

(c) (i) Open Access

\section{Abstract}

Background and Aims: Osteopenia and osteoporosis are frequently encountered with Inflammatory Bowel Disease (IBD). Our aims were to determine the prevalence of low bone mineral density (BMD) in patients with recently diagnosed IBD, and to assess predictive factors of reduced BMD. Patients and Methods: Prospective study conducted from January 2008 to December 2012 and involved patients with IBD treated in the Department of Gastroenterology of the Internal Security Forces Hospital. The data collected included: age, gender, body mass index (BMI), diagnostic delay, disease activity, and disease localization. Laboratory findings included serum calcium, phosphate, albumin, hemoglobin, and C-reactive protein. BMD was assessed by dual energy X-ray absorptiometry (DEXA) of the lumber spine and femoral neck. According to WHO criteria, osteopenia was defined as a T-score between $\mathbf{- 1}$ and $\mathbf{- 2}$ SD, and osteoporosis as a T-score less than $\mathbf{- 2}$ SD. Results: $A$ total of 34 patients (17 men, 17 women) were enrolled. Mean age was $37.1 \pm 13.8$ years (range 16 - 62). Twenty-two patients (65\%) had Crohn's disease (CD) and 12 patients (35\%) had ulcerative colitis (UC). Mean BMI was $20.5 \pm 4 \mathrm{~kg} / \mathrm{m}^{2}$. Low BMD occurred in $50 \%$ of patients (12 CD, $5 \mathrm{UC}$ ). Thirteen patients $(38.2 \%)$ exhibited osteopenia and 4 patients $(10.8 \%)$ showed osteoporosis. Mean vertebral T-score was $-0.933 \pm 1.41$ (range -4.1 to 1.7 ) and BMD in this site was $1.079 \pm 0.17$ $\mathrm{g} / \mathrm{cm}^{2}$ (range 0.674 to 1.380 ). Mean femoral T-score was $-0.398 \pm 1.2$ (range -3.1 to 2.4 ) and BMD in this site was $0.990 \pm 0.173 \mathrm{~g} / \mathrm{cm}^{2}$ (range 0.633 to 1.600 ). There was a positive correlation between T-score and albuminemia. Low BMI was found to be predictive factor of reduced BMD at the

${ }^{*}$ Corresponding author.

How to cite this paper: Cheikh, M., et al. (2015) Bone Mineral Density in Patients with Newly Diagnosed Inflammatory Bowel Disease: Frequency and Risk Factors in Tunisian Population. Results of a Prospective Study. Open Journal of Rheumatology and Autoimmune Diseases, 5, 126-130. http://dx.doi.org/10.4236/ojra.2015.54020 
moment of IBD diagnosis. However, no correlation was found between BMD and the other studied variables (age, gender, smoking, history of fracture, disease location, duration of disease, activity, small bowel resection, serum calcium level, phosphate, $C$-reactive protein and hemoglobin). Conclusion: Our study showed that the half of patients with IBD had a low BMD in newly diagnosed IBD patients. Low BMI and hypoalbuminemia were the major factors affecting BMD in these patients. Bone density measurement should be performed in all patients with IBD in an early stage of the disease.

Keywords

Osteopenia, Osteoporosis, Bone Mineral Density, Inflammatory Bowel Disease

\section{Introduction}

Patients with inflammatory bowel disease (IBD), including ulcerative colitis (UC) and Crohn's disease (CD), have been shown to be at increased risk of metabolic bone disease [1]. The pathogenesis of decreased bone mineral density (BMD) in IBD patients is multifactorial, complex, and only partly understood. Multiple risk factors such as the systemic use of corticosteroids, disease activity, malnutrition, vitamin D deficiency, smoking, and lack of physical activity are believed to be involved in the pathophysiology of IBD-associated osteoporosis. Osteoporosis may lead to low-impact fractures. The prevalence of osteoporosis and osteopenia in these patients varies among studies, as do the reported risk factors. However, few studies on the prevalence of bone disease have involved in patients with newly diagnosed IBD. This study is the first one to determine the prevalence of osteoporosis and osteopenia and to assess the risk factors for bone loss in Tunisian patients with recently diagnosed IBD.

\section{Patients and Methods}

\subsection{Patients}

All patients with newly diagnosed IBD $(n=34)$ during the study period from January 2008 to December 2012 at the Department of Gastroenterology of the Internal Security Forces Hospital, were asked to participate in the study. The patients were studied within 12 months of diagnosis that was based on findings from endoscopy with histology and/or radiology.

Disease activity in CD was assessed using the Crohn's Disease Activity Index (CDAI) and in UC according to the Truelove and Witts index. Patients with CD were considered to have active disease when CDAI was > 150 . To highlight the role of IBD in the development of osteoporosis in recently diagnosed patients, we excluded patients with predisposing factors of osteoporosis: concomitant diseases predisposing to secondary osteoporosis (thyroid disease, renal disease, diabetes, liver disease, or ankylosing spondylitis), duration of IBD more than 12 months and corticosteroids intake.

This study was approved by Ethics Committee and patients provided written informed consent.

\subsection{Methods}

Age, gender, body mass index (BMI), history of spontaneous or traumatic fractures, smoking, disease location and disease activity were recorded. Laboratory findings included serum calcium, phosphate, albumin, hemoglobin and C-reactive protein. BMD was measured using the dual-energy X-ray absorptiometry (DEXA) of lumbar spine and femoral neck, and was expressed in absolute values $\left(\mathrm{g} / \mathrm{cm}^{2}\right)$ and $\mathrm{T}$ score $(1$ standard deviation [SD] compared with a young adult gender-matched reference population). Osteopenia was defined as a T score between -1 and $-2.5 \mathrm{SD}$ and osteoporosis as a T score less than $-2.5 \mathrm{SD}$ according to the World Health Organization (WHO) classification [2].

\subsection{Statistical Analysis}

Analysis was performed using SPSS version 19. Results were expressed as mean \pm SD. An univariate analysis 
searching for the factors possibly associated with low bone density was firstly performed by comparison between patients with normal BMD and those with low BMD using Student $t$ test for continuous variables and the Chi-square or Fisher exact test for categorical variables. Then, a multivariate analysis based on a stepwise logistic regression model was used to assess the independent effect of variables found significant at the univariate analysis. A p-value of less than 0.05 was considered statistically significant.

\section{Results}

\subsection{Patients Population}

A total of 34 patients (17 females, 17 males) with IBD were enrolled in the study. They had a mean age of 37.1 \pm 13.8 years (range: 16 - 62). Twenty two patients had CD and twelve patients had UC. In the patients with CD, the disease was localized in the colon in $28 \%$ of patients, small bowel in $32 \%$ of patients, and both small bowel and colon in $40 \%$ of patients. In the UC group, $34 \%$ of patients had pancolitis, $41 \%$ of patients had distal colitis, and $25 \%$ of patients had proctitis. Mean BMI was $20.5 \pm 4 \mathrm{~kg} / \mathrm{m}^{2}$ (range: $14-32$ ). The median duration of IBD was 5.1 months. Regarding the activity of the disease, it was mild in $14.7 \%$ of patients, moderate in $44.1 \%$ of cases and severe in $42.2 \%$ of patients. Five patients with CD underwent small bowel resection. Only one patient had history of traumatic fracture. Nine patients (26\%) were active smokers.

Demographical and clinical characteristics are given in Table 1. Biochemical characteristics at baseline are shown in Table 2.

\subsection{BMD and Prevalence of Low Bone Density}

Low BMD occurred in 17 patients (50\%): 5 UC and 12 CD patients. Thirteen patients (38.2\%) showed osteopenia and 4 patients (10.8\%) exhibited osteoporosis. Mean vertebral T-score was $-0.93 \pm 1.41$ (range: -4.1 to 1.7 ) and BMD in this site was $1.07 \pm 0.17 \mathrm{~g} / \mathrm{cm}^{2}$ (range: 0.6 to1.3). Mean femoral T-score was $-0.39 \pm 1.2$ (range: -3.1 to 2.4) and BMD in this site was $0.99 \pm 0.17 \mathrm{~g} / \mathrm{cm}^{2}$ (range: 0.6 to 1.6). The BMD characteristics of patients with recently diagnosed IBD are shown in Table 3.

\begin{tabular}{lc} 
Table 1. Patient demographic and clinical characteristics. \\
\hline Characteristics & $\mathrm{N}=34$ \\
Age (years) & $37.1 \pm 13.8(16-62)$ \\
Sex (F/M) & $17 / 17$ \\
Smoking & $9(26 \%)$ \\
BMI $\left(\mathrm{kg} / \mathrm{m}^{2}\right)$ & $20.5 \pm 4(14-32)$ \\
Duration of complaints (months) & 5.1 \\
Location in CD: & \\
$\quad$ Small intestine & $7(32 \%)$ \\
$\quad$ Colon & $6(28 \%)$ \\
$\quad$ Both & $9(40 \%)$ \\
Location in UC: & \\
$\quad$ Pancolitis & $4(34 \%)$ \\
$\quad$ Distal colitis & $5(41 \%)$ \\
$\quad$ Proctitis & $3(25 \%)$ \\
Disease activity: & \\
$\quad$ Mild & $5(14.7 \%)$ \\
$\quad$ Moderate & $15(44.1 \%)$ \\
$\quad$ Severe & $14(42.2 \%)$ \\
Small bowel resection & 5 \\
\hline
\end{tabular}


Table 2. Patient biochemical characteristics at baseline.

\begin{tabular}{cc}
\hline Parameters & \\
\hline Calcium $(\mathrm{mg} / \mathrm{L})$ & $90 \pm 9(68-102)$ \\
Phosphate (mg/L) & $35 \pm 9(21-88)$ \\
Albumin (g/dL) & $30.2 \pm 7(15-42)$ \\
Hemoglobin (g/dL) & $11 \pm 1(6.6-14.5)$ \\
CRP (mg/dL) & $50 \pm 30(2-178)$ \\
\hline
\end{tabular}

Table 3. Bone mineral density characteristics in patients with newly IBD.

\begin{tabular}{ccc}
\hline & BMD $\left(\mathrm{g} / \mathrm{cm}^{2}\right)$ & T-score (SD) \\
\hline Lumbar spine (L2-L4) & $1.07 \pm 0.17[0.6-1.3]$ & $-0.93 \pm 1.41[-4.1-1.7]$ \\
Femoral neck & $0.99 \pm 0.17[0.6-1.6]$ & $-0.39 \pm 1.2[-3.1-2.4]$ \\
\hline
\end{tabular}

\subsection{Risk Factors of Low BMD}

Loss of bone density was more frequent in CD than in UC patients without significant difference. There was a positive correlation between T-score and albuminemia $(p=0.03)$. Low BMI was found to be predictive factor of reduced $B M D$ in patients with recently diagnosed IBD $(p=0.05)$. However, there were no statistically differences between patients with normal BMD and those with reduced mineral density regarding age, gender, smoking, history of fracture, disease location, duration of disease, activity, small bowel resection, serum calcium level, phosphate, C-reactive protein and hemoglobin.

\section{Discussion}

This study found that the prevalence of osteoporosis and osteopenia was higher than previously reported [3]. Previous studies identified predictors of bone loss in patients with IBD. Low BMI is associated with a higher risk of bone disease [4]-[7]. BMI $<20 \mathrm{~kg} / \mathrm{m}^{2}$ was found to be a risk factor for low bone mass at the time of IBD diagnosis [3]. In consistent with these results, our study also suggested low BMI is a risk factor of loss of BMD in patients with recently diagnosed IBD. Measurements of calcium level in these IBD patients showed that they were not at risk for low BMD. Duration of complaints longer than 6 months before diagnosis was identified to be a risk factor for low bone mass at the time of IBD diagnosis [3]. Therefore, BMD should be measured at diagnosis in patients with long-term undiagnosed and untreated complaints of IBD type. In contrast, in our study, there was no correlation between duration of disease and reduced BMD. Loss of bone density has been reported to be more pronounced in CD than in UC patients [8]-[10]. This may be due to malabsorption, particularly in CD patients who have undergone surgical resection of the small bowel. However, other studies, including ours, have shown little or no difference between UC and CD patients [11] [12]. Unlike previous studies, we found that age, prior fracture, disease duration, disease-associated inflammation, and smoking were not associated with bone loss. In our study, male sex was not significantly associated with bone loss, in contrast to results showing that male sex was strong predictor of bone disease [5] [6].

The strength of our study is that it is the first one carried on a Tunisian population, allowing a preliminary determination of the prevalence and risk factors of low BMD in patients with newly diagnosed IBD.

Nevertheless, our study had limitations:

- The absence of control group without IBD. However, we did not feel it was ethically justified to do DEXA for a control group in absence of clinical indication.

- Serum vitamin D level was not measured in our study.

\section{Conclusion}

In our study, the half of patients with newly diagnosed IBD had reduced bone density. Low BMI and hypoalbuminemia were the major factors affecting BMD in patients with recently diagnosed IBD. In this way, control 
of disease activity and therapeutic management, started early in the course of the disease, particularly in patients with denutrition, may be successful in preventing osteoporosis in IBD.

\section{References}

[1] Bjarnason, I., Macpherson, A., Mackintosh, C., Buxton-Thomas, M., Forgacs, I. and Moniz, C. (1997) Reduced Bone Density in Patients with Inflammatory Bowel Disease. Gut, 40, 228-233. http://dx.doi.org/10.1136/gut.40.2.228

[2] (1994) Assessment of Fracture Risk and Its Application to Screening for Postmenopausal Osteoporosis. Report of a WHO Study Group. World Health Organization Technical Report Series, 843, 1-129.

[3] Ezzat, Y. and Hamdy, K. (2010) The Frequency of Low Bone Mineral Density and Its Associated Risk Factors in Patients with Inflammatory Bowel Diseases. International Journal of Rheumatic Diseases, 13, 259-265. http://dx.doi.org/10.1111/j.1756-185X.2010.01542.x

[4] Kornbluth, A., Hayes, M., Feldman, S., Hunt, M., Fried-Boxt, E., Lichtiger, S., et al. (2006) Do Guidelines Matter? Implementation of the ACG and AGA Osteoporosis Screening Guidelines in Inflammatory Bowel Disease (IBD) Patients Who Meet the Guidelines' Criteria. American Journal of Gastroenterology, 101, 1546-1550. http://dx.doi.org/10.1111/j.1572-0241.2006.00571.x

[5] Jahnsen, J., Falch, J.A., Mowinckel, P. and Aadland, E. (2004) Bone Mineral Density in Patients with Inflammatory Bowel Disease: A Population-Based Prospective Two-Year Follow-Up Study. Scandinavian Journal of Gastroenterology, 39, 145-153. http://dx.doi.org/10.1080/00365520310007873

[6] Wada, Y., Hisamatsu, T., Naganuma, M., et al. (2015) Risk Factors for Decreased Bone Mineral Density in Inflammatory Bowel Disease: A Cross-Sectional Study. Clinical Nutrition. http://dx.doi.org/10.1016/j.clnu.2015.01.003

[7] Schoon, E.J., Blok, B.M., Geerling, B.J., Russel, M.G., Stockbrügger, R.W. and Brummer, R.J. (2000) Bone Mineral Density in Patients with Recently Diagnosed Inflammatory Bowel Disease. Gastroenterology, 119, 1203-1208. http://dx.doi.org/10.1053/gast.2000.19280

[8] Vestergaard, P., Krogh, K., Rejnmark, L., Laurberg, S. and Mosekilde, L. (2000) Risk Is Increased in Crohn’s Disease, but Not in Ulcerative Colitis. Gut, 46, 176-181. http://dx.doi.org/10.1136/gut.46.2.176

[9] Jahnsen, J., Falch, J.A., Aadland, E. and Mowinckel, P. (1997) Bone Mineral Density Is Reduced in Patients with Crohn's Disease but Not in Patients with Ulcerative Colitis: A Population Based Study. Gut, 40, 313-319. http://dx.doi.org/10.1136/gut.40.3.313

[10] Ghosh, S., Cowen, S., Hannan, W.J. and Ferguson, A. (1994) Low Bone Mineral Density in Crohn’s Disease, but Not in Ulcerative Colitis, at Diagnosis. Gastroenterology, 107, 1031-1039.

[11] Siffledeen, J.S., Fedorak, R.N., Siminoski, K., Jen, H., Vaudan, E., Abraham, N., et al. (2004) Bones and Crohn's: Risk Factors Associated with Low Bone Mineral Density in Patients with Crohn's Disease. Inflammatory Bowel Diseases, 10, 220-228. http://dx.doi.org/10.1097/00054725-200405000-00007

[12] Ardizzone, S., Bollani, S., Bettica, P., Bevilacqua, M., Molteni, P. and Bianchi Porro, G. (2000) Altered Bone Metabolism in Inflammatory Bowel Disease: There Is a Difference between Crohn's Disease and Ulcerative Colitis. Journal of Internal Medicine, 247, 63-70. http://dx.doi.org/10.1046/j.1365-2796.2000.00582.x 